\title{
TeleMídia and 3D Hypermedia Research
}

\author{
Luiz Fernando Gomes Soares, Roberto Gerson de Albuquerque Azevedo, Márcio Ferreira Moreno \\ Department of Informatics \\ Pontifical Catholic University of Rio de Janeiro \\ Rio de Janeiro, RJ, Brazil \\ lfgs@inf.puc-rio.br, \{robertogerson, marcio\}@ telemidia.puc-rio.br
}

\begin{abstract}
This paper presents the TeleMídia Lab, its history, objectives, research lines, and current research and innovation topics. Among these topics we can find the Hypermedia and Multimedia 3D systems, with support to augmented reality.
\end{abstract}

Keywords-TeleMídia; Nested Context Language; Virtual Reality; AugmentedReality; Hypermedia; Multimedia;

\section{INTRODUCTION}

Several Thematic Research Laboratories make up the Institute of Software Technology (ITS) at the Informatics Department of the Pontiphical Catholic University of Rio de Janeiro (PUC-Rio). Among these units is the TeleMídia Lab ${ }^{1}$, which supports Multimedia/Hypermedia System and Multimedia Data Communication researches. In particular, both terrestrial Digital TV systems and IPTV systems have been the research and innovation focuses of TeleMídia in the recent years, and more recently 3D interactive Digital TV.

Digital TV systems are special cases of hypermedia systems. In this domain TeleMídia is concerned with research about domain specific declarative languages to express relationships among media objects, in particular temporal and spatial relationships, which compound a hypermedia application. With this perspective, the NCL (Nested Context Language) was conceived and its execution machine, named Ginga-NCL. NCL and Ginga-NCL became part of the International Standard for Digital Broadcasting (ISDB-T $\mathrm{B}_{\mathrm{B}}$ ) in 2007, and the first middleware solution standardized by ITU-T for IPTV services in 2009 [1]. For the first time in the ICT area Brazil contributed with an innovative standard.

Ginga-NCL is indeed a multimedia presentation orchestrator for a distributed environment composed of multiple exhibition and capturing devices. Therefore, its use both in multi-device home networks for distributed DTV presentation and in augmented reality environments came up naturally. More recently our efforts have turned to include in NCL support for 3D objects and to allow interactions via multimodal interfaces.

${ }^{1}$ TeleMídia Lab is located at: Rua Marquês de São Vicente 225, Edifício Pe. Belizário (ITS - Instituto de Tecnologia de Software). Gávea - Rio de Janeiro/RJ - Brasil. CEP: 22.453900

\section{A LITTLE BIT OF OUR HISTORY}

Formally, TeleMídia Laboratory was founded in 1995, but its origins remains in the 80's when the Computer Network Group was created inside the Department of Informatics at PUC-Rio. The Computer Network Group was responsible by the REDPUC (one of the two first Brazilian computer networks and one of the first networks transmitting above $10 \mathrm{Mbps}$ ).

In the 90's TeleMídia has developed important applications, such as teleconference systems, and multimedia mail systems, in joint research with IBM Scientific Center of Rio de Janeiro. Soon, TeleMidia researchers realized, like other groups in other countries, the necessity of a formal treatment to documents interchanged among various multimedia applications. Thus, the start of a joint PUC-IBM project in the field of Hypermedia Applications, named HyperProp, was naturally born. HyperProp was conceived as an open distributed hypermedia system to support hypermedia facilities to user applications.

In 1991, the Hypermedia data model developed in the scope of the HyperProp project, named NCM (Nested Context Model), solved an open issue in the Hypermedia Systems domain. In 1992, the proposed solution was incorporated to ISO MHEG standard. MHEG became the first digital TV middleware, adopted in the England until nowadays.

With the knowledge accumulated over two decades of experiences in the Hypermedia/Multimedia Systems, in 2005 the HyperProp's researchers move their focus to the Interactive Digital Television domain, resulting in the Ginga-NCL subsystem. In 2006, the Ginga-NCL was adopted as the declarative middleware of the Brazilian Standard for Terrestrial Digital TV. Part of ISDB-T I $_{\mathrm{B}}$, this solution is adopted today in 16 countries around the world. In 2009, Ginga-NCL was approved as the ITU-T H.761 Recommendation for IPTV services.

Ginga-NCL was devised for multi-device home networks. Its use in augmented reality environments came up naturally. Moreover, as a glue language NCL can embed with advantages $3 \mathrm{D}$ objects, both in 2D and 3D worlds. As expected these features initiates a series of work in these domains, in particular in 3D digital TV support.

Simultaneous to its researches and scientific productions, TeleMídia prioritizes the training of human resources. Several courses have been offered regularly by the laboratory. Over a 
hundred Doctors and Masters have been formed by TeleMídia. Most of these professionals are working in important institutions, such as universities, research institutes, private and public enterprises, government agencies, among others, widespreading the knowledge acquired in the Lab during their training.

\section{RESEARCH LINES AND CURRENT GOALS}

Today, TeleMídia's research lines include:

- Hypermedia and multimedia system architecture

- Hypermedia and multimedia applications (including 3D applications)

- Structure-based declarative languages (including support for 3D objects and relationships)

- Declarative presentation environments (including multi-device environments with multimodal interactions)

- Distributed multimedia processing

These research lines run in strict cooperation and relationship with other research lines: Virtual, Augmented and Mixed Reality; Human-Computer Interaction; Web Semantics; and Computer Networks.

Nowadays, the main focus of TeleMídia's research initiatives is the development of a new version of NCL (the version 4.0) and its execution engine. Two language profiles are being designed. The first one (NCL Raw Profile) trying to reduce the semantic gap between the application specification model and the presentation data model used in the NCL engine (Ginga-NCL). The second one trying to extend NCL and Ginga-NCL: to improve their support to multi-device environments, to include semantic descriptions of interactive narratives (today barely supported), and to improve the support offered to 3D applications. Concerning this last issue, we are currently researching 3D Hypermedia/Multimedia Systems and Augmented Reality aiming at finding how their particular features could be supported declaratively by using NCL in its new version.

\section{ONGOING PROJECTS}

At the moment, TeleMídia is working on the following projects: Reference Implementation of Ginga-NCL;Composer; $S A G G A$ (Support to Automatic Generation of Ginga-NCL Applications); NCL version 4.0; and IPTV.br.

The Reference Implementation project aims to develop new middleware architecture for Digital TV systems with support to multiple distributed exhibition devices and multimodal input devices. The new architecture is used as the basis of virtual environments, in particular those found in Social TV services.

Composer project aims at creating an extensible authoring environment for NCL applications. SAGGA is directly related with Composer and focus on creating an infrastructure to automatically generate dynamic hypermedia applications based on templates describing families of applications.
The new version of NCL, already mentioned in Section III, aims to offer:

- Better support to context aware applications;

- Better support to distributed applications using multiple devices, including Social TV services;

- Support to new multimodal input devices (e.g. multitouch devices, Kinect, etc.)

- Declarative support to applications with dynamic contents;

- Support to constraint relationships among media objects in addition to the causal relationships currently provided;

- Support to relationship definition automatically inferring the relations involved;

- Support to 3D objects;

$\circ$ exhibition of 2D objects over 3D surfaces;

$\circ$ embedding 3D objects inside NCL, for example, using other declarative languages (X3D, Collada, etc.);

- support to relationships based on 3D events (for instance, collision, proximity, etc.); and

- Declarative management of behavior of 3D objects that may be embed in NCL applications.

Thus, 3D Multimedia Coding, Virtual Reality and Augmented Reality Hypermedia Applications are some of our current research efforts to extend NCL capabilities with regard to $3 \mathrm{D}$ support. The overall goal is allowing authors to specify 3D applications through using the declarative (and thus much simpler) paradigm.

As NCL has a stricter separation between content and structuring, it does not define any media type by itself. Instead, it defines the glue that holds media content together in multimedia presentations. NCL document only defines how media objects are structured and related, in time and space. As a glue language, it does not restrict or prescribe any mediaobject content type. Thus, the first step to integrate NCL with other declarative languages (including languages that support the definition of three-dimensional worlds, like VRML [2], X3D [3], XMT [4], Collada [5], and so on) is creating new players that can be easily embedded in the Ginga-NCL engine.

Other work also follow the same direction [6] [7] we propose, but with some restrictions. Our reference [8] is the single work that realizes that NCL can also define anchoring points inside 3D worlds integrated into Hypermedia applications. Moreover, using the approach presented in [8], it is also possible to control the whole $3 \mathrm{D}$ application behavior through using NCL entities. As a use case presented in reference [8], an $\mathrm{OBJ}$ and an X3D player ${ }^{2}$ were integrated to the Ginga-NCL reference implementation allowing simple and composite 3D objects in NCL documents, respectively. Moreover, by using multiple device features, it was also possible to have distributed hypermedia applications with embed 3D objects, like the one presented on the work and depicted in Figure 1.

However, the NCL solution for embedding 3D objects still needs some improvements. For example, we also have some issues related to stereoscopic videos (in a 3DTV environment

${ }^{2}$ The X3D player integrated to the Ginga-NCL was the FreeWRL (available at http://freewrl.sourceforge.net). 
the main video sent by broadcasters) and their relation with the remaining interactive application to be solved. Of course, a lot of issues related to user interaction with $2 \mathrm{D}$ and $3 \mathrm{D}$ mixed content (including multiple devices) also deserves attention and are within our research interest.

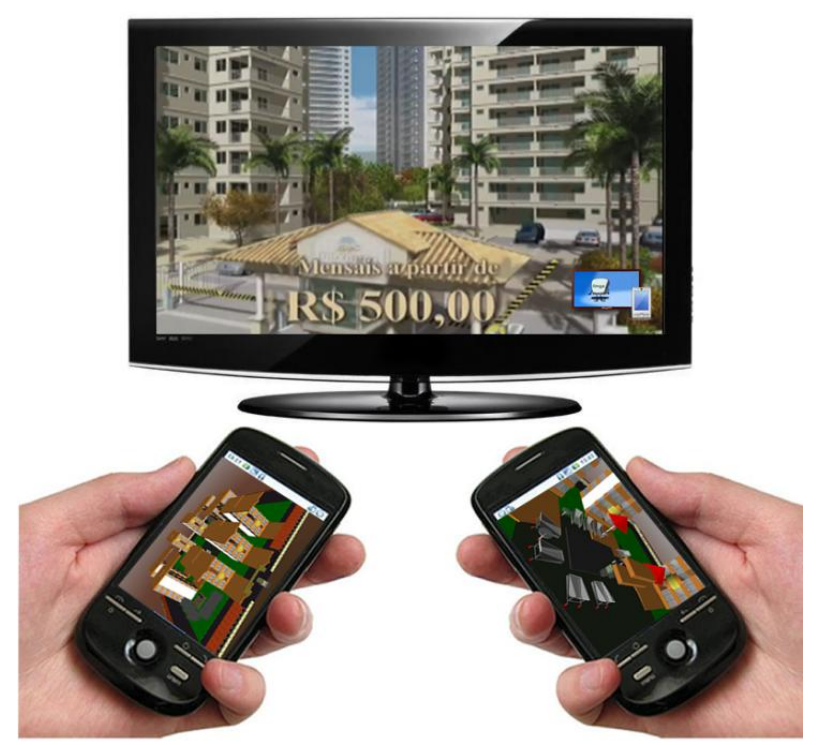

Figure 1 NCL application with embedded X3D media objects running on multiple secondary devices.

With regards to the IPTV.br project (www.iptv.br), we are working on an experimental infrastructure to provide interconnection and interoperability to new multimedia services, focusing on social inclusion. The project allows for testing and deploying real digital TV applications. The interoperability will be initially supported by using Web and Digital TV standards. In a second phase, this project will support the new NCL Raw profile, being developed together with other research groups (through a liaison led by PUC-Rio as ITU-T, CWI as W3C and NIC.br as W3C Brazil), aims at becoming a common base to interoperate IPTV middleware. IPTV.br will also serve as platform to test virtual and augmented reality environments based on NCL 4.0, in particular those focusing on Social TV services.

The IPTV.br project has also a social leg, called Ginga Brasil (http://gingabrasil.ginga.org.br). The main goal is teaching community TVs, university TVs and other audiovisual NGO to create Digital hypermedia applications, in especial interactive narratives, targeting interactive TV and interactive movies.

\section{CONCLUSIONS}

After this brief presentation of the TeleMídia Lab, its main goals and its current research projects, we finish inviting readers to visit the Lab's site at http://www.telemidia.puc-rio.br to obtain more details about work being done, including all published papers and thesis. From this site, other sites concerned to each individual project in developing at the Lab can be reached. The contact with us can be made by email: info@telemidia.puc-rio.br, for more information or to join us as welcome partners.

\section{REFERENCES}

[1] ITU-T Recommendation H.761, 2009. Nested Context' Language (NCL) and Ginga-NCL for IPTV Services. Geneva, April, 2009.

[2] WEB3D CONSORTIUM. The Virtual Reality Modeling Language (VRML), Part 1 - Functional specification and UTF-8 encoding., 1997. Disponivel em: 〈http://www.web3d.org/x3d/specifications>.

[3] WEB3D CONSORTIUM. "Extensible 3D (X3D)", ISO/IEC 197761.2:2009, 2009. Available at: http://www.web3d.org/x3d/specifications.

[4] Kim, M., Wood, S. and Cheok, L, "Extensible MPEG-4 Textual Format (XMT)". 2000 ACM Workshops on Multimedia, Los Angeles, Nov. 2000.

[5] Arnaud, R. and Barnes, M. C. "Collada: Sailing the Gulf of 3d Digital Content Creation”. AK Peters Ltd, 2006.

[6] Tavares, D. C. et al "Interactive Virtual Worlds in Brazilian Digital Television". Workshop on Interactive Digital TV in Emergent Countries at EuroITV 2010, Tampere, Finland. 9th June, 2010.

[7] Souza, D. F. L., Machado, L. S. and Tavares, T. A.: "3D Technologies to Extend Brazilian DTV Middleware" SBC Journal on 3D Interactive Systems, Vol.2 N.1, 2011. ISSN: 2236-3297.

[8] R. G. Azevedo. "Suporte ao controle e à apresentação de objetos de mídia tridimensionais em NCL". Master Thesis, Pontifical Catholic University of Rio de Janeiro (PUC-Rio), Brazil, August, 2010. 